\title{
Suppressor of cytokine signalling gene expression is elevated in breast carcinoma
}

\author{
M Raccurt ${ }^{1,5}$, SP Tam ${ }^{2,5}$, P Lau' ${ }^{2}$, HC Mertani', A Lambert', T Garcia-Caballero ${ }^{3}$, H Li $^{2}$, RJ Brown ${ }^{2}$, \\ MA McGuckin ${ }^{4}$, G Morel' $^{\prime}$ and MJ Waters*,2
}

'CNRS UMR 5 I 23, Bât. Raphael Dubois, Université Claude Bernard-Lyon I, 43 Blvd I I Novembre 1918, F69622 Villeurbanne cedex, France; '2 School of Biomedical Sciences and Institute for Molecular Bioscience, University of Queensland, St Lucia, Queensland 4072, Australia; ${ }^{3}$ Departamento de Ciencias Morfológicas, Facultad de Medicina, Universidad Santiago de Compostela, c/San Francisco s/n, Santiago de Compostela I5705, Spain; ${ }^{4}$ Mater Medical

Research Institute, Level 3, Aubigny Place, Mater Misericordiae Hospital, S. Brisbane, Queensland 4I01, Australia

Cytokines are important for breast cell function, both as trophic hormones and as mediators of host defense mechanisms against breast cancer. Recently, inducible feedback suppressors of cytokine signalling (SOCS/JAB/SSI) have been identified, which decrease cell sensitivity to cytokines. We examined the expression of SOCS genes in 17 breast carcinomas and 10 breast cancer lines, in comparison with normal tissue and breast lines. We report elevated expression of SOCS-I -3 and CIS immunoreactive proteins within in situ ductal carcinomas and infiltrating ductal carcinomas relative to normal breast tissue. Significantly increased expression of SOCS-I - 3 and CIS transcripts was also shown by quantitative in situ hybridisation within both tumour tissue and reactive stroma. CIS transcript expression was elevated in all 10 cancer lines, but not in control lines. However, there was no consistent elevation of other SOCS transcripts. CIS protein was shown by immunoblot to be present in all cancer lines at increased levels, mainly as the $47 \mathrm{kDa}$ ubiquitinylated form. A potential proliferative role for CIS overexpression is supported by reports that CIS activates ERK kinases, and by strong induction in transient reporter assays with an ERK-responsive promoter. The in vivo elevation of SOCS gene expression may be part of the host/tumour response or a response to autocrine/paracrine GH and prolactin. However, increased CIS expression in breast cancer lines appears to be a specific lesion, and could simultaneously shut down STAT 5 signalling by trophic hormones, confer resistance to host cytokines and increase proliferation through ERK kinases.

British Journal of Cancer (2003) 89, 524-532. doi:I0.I038/sj.bjc.660 I I 5 www.bjcancer.com

(C) 2003 Cancer Research UK

Keywords: cytokine; SOCS; breast; prolactin; growth hormone; carcinoma

Cytokines are key regulators of mammary epithelial cell function, exerting regulatory actions on proliferation, differentiation, apoptosis and immune surveillance. For example, mammary ductal proliferation and branching is promoted by growth hormone (Silberstein and Daniel, 1987), while alveolar cell proliferation and secretory function require the presence of prolactin (Vonderhaar, 1987). Epidemiologic evidence indicates a role of prolactin in both the pathogenesis and progression of breast cancer (Hankinson et al, 1999). However, both of these cytokine hormones can promote proliferation of breast cancer lines (Fuh and Wells, 1995; Kaulsay et al, 1999) and their receptors are expressed in a wide variety of breast cancers (Clevenger et al, 1995; Mertani et al, 1998). Both can also be synthesised locally in the mammary gland (Clevenger et al, 1995; Reynolds et al, 1997), and antagonists of the prolactin and growth hormone (GH) receptors are able to inhibit proliferation of breast cancer lines (Fuh and Wells, 1995). Moreover, autocrine production of GH in human mammary cell lines promotes the transformed phenotype

*Correspondence: Dr MJ Waters; E-mail: m.waters@mailbox.uq.edu.au ${ }^{5}$ The first two authors contributed equally to this work.

Received 16 December 2002; revised 28 April 2003; accepted 7 May 2003
(Kaulsay et al, 1999), and prolactin increases the motility of breast cancer lines (Maus et al, 1999).

Cytokine receptors exert their actions through activation of the Janus kinases (JAKs), which tyrosine phosphorylate both the receptors and their downstream signalling targets, notably the STAT family of transcriptional activators (Argetsinger and Carter$\mathrm{Su}, 1996)$. The major STATs responsible for regulation of the mammary gland by $\mathrm{GH}$ and prolactin are STAT $5 \mathrm{a}$ and $5 \mathrm{~b}$ (Teglund et al, 1998), both receptors are also able to activate STAT 3 (Argetsinger and Carter-Su, 1996). Immune cytokines such as the interferons also utilise JAKs, and play an important role in mediating the host response to development of breast cancer (Allione et al, 1994; Camp et al, 1996; Tannenbaum and Hamilton, 2000).

Recently, it has been shown that cytokine signalling through the JAK/STAT pathway is controlled by a classical feedback loop through suppressors of cytokine signalling (SOCS/JAB/SSI) (Hilton, 1999). Suppressors of cytokine signalling proteins are rapidly induced by activated STATs and act to block the cytokine signal either by direct inhibition of JAKs (SOCS-1), by binding to tyrosine phosphorylated receptor so as to exclude binding of other SH2 and PTB domain-containing signalling proteins such as STATs (CIS), or by both mechanisms (SOCS-3) (Ram and Waxman, 1999). SOCS proteins are also able to accelerate proteasome-mediated destruction of the activated cytokine- 
receptor complex (Ram and Waxman, 2000; Kamizono et al, 2001), particularly in the case of CIS. These inhibitory regulators not only attenuate the signal from the activated cytokine receptor itself, but can also decrease cell sensitivity to other cytokines and hormones, such as insulin (Emanuelli et al, 2000). Thus, prolactin, the major trophic cytokine for the breast, is known to rapidly induce SOCS$1-3$ and CIS, and this results in loss of sensitivity to subsequent prolactin challenge (Tam et al, 2001). SOCS-1 has been shown to be critical for preventing interferon $\gamma$ (IFN $\gamma$ )-mediated growth arrest of M-1 myeloid cells (Sakamoto et al, 1998), and overexpression of SOCS-1 or SOCS-3 in breast cancer lines inhibits the antiviral and antiproliferative ability of IFN $\gamma$ (Song and Shuai, 1998). Interestingly, there is evidence that mammary carcinoma lines are resistant to the growth inhibitory actions of IFN $\gamma$ (Harvat and Jetten, 1996), which could be the result of constitutive expression of SOCS proteins. Indeed, constitutive SOCS-3 expression has been reported for cutaneous T-cell lymphoma lines, and reversal of this expression was associated with increased sensitivity to interferon $\gamma$ inhibition of proliferation (Brender et al, 2001).

In view of the importance of SOCS expression in regulation of mammary cell function, and its potential importance in breast cancer, we have examined the expression of SOCS-1-3 and CIS in both breast cancers and in breast cancer lines. The former provides information about SOCS expression in vivo in the context of host responses, while the latter allows for demonstration of constitutive expression that may result from genomic alteration.

\section{MATERIALS AND METHODS}

\section{Tissue samples}

Surgical samples of breast cancer were selected from the files of University Clinical Hospital of Santiago de Compostela (Pr. Forteza) (Spain), which had been collected with Institutional Ethics Committee approval. A total of 20 human breast samples defined by standard histopathological criteria were studied: three normals, six in situ ductal carcinomas without lymph node metastasis, and 11 infiltrating ductal carcinomas. Tissues were fixed in $10 \%$ buffered formalin for $24 \mathrm{~h}$ at room temperature, dehydrated, embedded in paraffin and sectioned by standard procedure. Sections of $5 \mu \mathrm{m}$ thick were mounted on sterilised 3aminopropyl-triethoxysilane-coated slides (Sigma, St Louis, MO, USA) and dewaxed before processing for in situ hybridisation or immunohistochemistry.

\section{Cell lines}

The BT-20, MA-11, MDA-MB-468, SK-BR-3, KPL-1, T-47D, UACC893, ZR-75-1 and ZR-75-30 cell lines were obtained from American Type Culture Collection (Manassas, VA, USA) and grown in RPMI 1640 medium supplemented with 10\% FCS. The HMEC184, MCF$10 \mathrm{~A}$ and MCF7 cell lines were gifts from Dr R Sutherland (Garvan Institute, Sydney, Australia). The HMEC184 cell line was grown in MCDB 170 culture medium supplemented with bovine pituitary extract (Gibco BRL, Rockville, MD, USA) and $5 \mu \mathrm{g} \mathrm{ml}^{-1}$ gentamycin. The MCF-10A cell line was grown in DMEM: Hams F12 $(1: 1)$ supplemented with $20 \mathrm{ng} \mathrm{ml}^{-1} \mathrm{EGF}, 10 \mu \mathrm{g} \mathrm{ml}^{-1}$ insulin, $500 \mathrm{ng} \mathrm{ml}^{-1}$ hydrocortisone, $2.5 \mathrm{mmoll}^{-1}$ L-glutamine, $5 \%$ horse serum and $5 \mu \mathrm{g} \mathrm{ml}^{-1}$ gentamycin. The MCF7 cell line was cultured in RPMI 1640 medium supplemented with $10 \%$ Serum Supreme (a fetal bovine serum alternative supplied by Biowhittaker, USA) and $5 \mu \mathrm{g} \mathrm{ml}^{-1}$ gentamycin.

\section{Probes and antibodies}

Full-length cDNA probes were used to detect SOCS 1, 2 and 3, and CIS mRNAs (Starr et al, 1997). The human prolactin receptor probe was directed to the extracellular domain, nucleotides
346-1001 (Boutin et al, 1989). The human GH receptor probe was also directed to the extracellular domain, nucleotides 1-720 (Godowski et al, 1989). These probes were labelled with $\alpha\left[{ }^{35}\right.$ S $]$ dATP (NEN Life Sciences, Boston, MA, USA) by random priming and then purified from the free nucleotides with Nick Columns (Amersham Pharmacia Biotech AB, Sweden) according to the suppliers' instructions.

Goat antibody raised against a peptide corresponding to the carboxy terminal sequence of human SOCS-1 (cat. no. sc-7005, $\mathrm{C} 20$ ) and to the amino-terminal sequence of human CIS (cat. no. sc-1529, N-19) were purchased from Santa Cruz Biotechnology (Santa Cruz, CA, USA). Rabbit anti-CIS antibody was a generous gift of Professor Yoshimura, Institute of Life Science, Kurume, Japan (described in Matsumoto et al (1997)). Rabbit anti-SOCS-3 antibody was raised against murine SOCS-3, and was a generous gift of Dr Doug Hilton (Walter \& Eliza Hall Institute, Parkville, Australia). The streptavidin-avidin-peroxidase complex procedure was employed with diaminobenzidine as chromogen (Duet kit, Dakopatts, Carpinteria, CA,USA).

\section{In situ hybridisation}

Dewaxed sections were digested with $5 \mu \mathrm{g} \mathrm{ml}^{-1}$ proteinase $\mathrm{K}$ (Roche Diagnostics, Meylan, France) in a Tris $\left(20 \mathrm{mmoll}^{-1}\right)-\mathrm{CaCl}_{2}$ $\left(2 \mathrm{mmoll} \mathrm{l}^{-1}\right)$ buffer for $30 \mathrm{~min}$ at $37^{\circ} \mathrm{C}$. The slides were dehydrated in ethanol series and air-dried. Sections were then covered with hybridisation buffer containing $50 \%$ deionised formamide, $10 \%$ dextran sulphate, $4 \times$ standard saline citrate (SSC) $(1 \times$ $\mathrm{SSC}=0.15 \mathrm{moll}^{-1} \mathrm{NaCl}, 0.015 \mathrm{moll}^{-1}$ sodium citrate, $\mathrm{pH} 7.0$ ), $1 \times$ Denhardt's solution $(50 \times$ Denhardt's solution $=1 \%$ BSA, $1 \%$ Ficoll $400,1 \%$ polyvinylpyrolidone), $100 \mu \mathrm{g} \mathrm{ml}^{-1}$ yeast transfer RNA, $10 \mathrm{~mm}$ dithiothreitol and labelled probe $\left(5000\right.$ d.p.m. $\mu \mathrm{l}^{-1}$ corresponding to $0.1-0.5 \mu \mathrm{g} \mathrm{ml}^{-1}$ of hybridisation buffer). In situ hybridisation was performed overnight at $40^{\circ} \mathrm{C}$. Sections were washed sequentially in $2 \times$ SSC for $1 \mathrm{~h}$ at room temperature, then for $1 \mathrm{~h}$ at $45^{\circ} \mathrm{C}$ and subsequently in $1 \times$ SSC, followed by $0.5 \times$ SSC and $0.1 \times$ SSC, each for $30 \mathrm{~min}$ at room temperature. For macroautoradiography, dehydrated sections were apposed onto autoradiographic films (Hyperfilm $\left[{ }^{3} \mathrm{H}\right]$, Amersham-Pharmacia, Orsay, France) for 1 week at room temperature. For microautoradiographical purposes, the slides were dipped in NTB2 nuclear emulsion (Kodak, Paris, France), exposed at $4^{\circ} \mathrm{C}$ for 30 days, developed in D19 (Kodak), and finally counterstained with eosinhaemalum. Slides were observed under a fluorescent light microscope by epipolarisation. Controls for the specificity of the in situ hybridisation included: (1) omission of the probe; (2) hybridisation with a heterologous labelled POMC cDNA probe, (3) hybridisation with undenaturated labelled cDNA probe and (4) excess of nonlabelled probe.

\section{Semiquantification of the in situ hybridisation}

A semiquantitative analysis of gene expression was performed as previously described (Peyrol et al, 1997; Mertani et al, 1998) on more than six macroautoradiograms from each sample obtained under similar conditions. Sections were run through the same hybridisation, washing, and detection assays in order to render the signal levels comparable for each probe. The levels of mRNA were analysed in histopathological structures identified from contiguous sections stained with classical haematoxylin/phloxine/saffron (HPS). We quantified the grey level obtained on film in two compartments of normal tissues (duct and surrounding normal connective tissue), in infiltrating ductal breast carcinomas (cancerous area and normal connective tissue) and in three compartments of in situ ductal breast carcinomas (cancerous duct, epitheliostromal interface and normal connective tissue). Normal connective tissue was analysed as far away as possible from the tumor. Autoradiograms were analysed under standardised 
conditions, using a densitometric computer imaging system (Leica, Lyon, France). Optical densities for each sample were measured, in homogeneous areas (5-15/autoradiogram, excluding artefacts) and then averaged. Background signal was measured on negative control samples and substracted from each measure. A linear relationship (standard curve) with a slope depending on exposure time, was found by single regression analysis between optical density values of the standards and their corresponding radioactivity. It was then possible to compare the different radioactivity values for each probe used, which were expressed in arbitrary units, by inserting the optical density value of each sample into the standard curve equation. The levels of the signals obtained after hybridisation were expressed as the mean \pm s.e. Statistical analysis was performed using one-way analysis of variance, followed by Student's $t$-test. Differences were considered significant at $P<0.05$.

\section{Northern Hybridisation}

Total RNA was isolated from cell lines using TRIzol Reagent (Gibco BRL, Rockville, MD, USA) according to the manufacturer's protocol. Aliquots of $20 \mu \mathrm{g}$ total RNA were denatured and subjected to electrophoresis on a $1.2 \%$ agarose, $11 \%$ formaldehyde gels, then transferred to HyBond $\mathrm{N}$ membrane (Amersham Pharmacia Biotech, Buckinghamshire, UK). RNA was stabilised by UV-crosslinking and baking for $30 \mathrm{~min}$ at $80^{\circ} \mathrm{C} .{ }^{32} \mathrm{P}$-labelled cDNA probes specific for SOCS-1, $-2,-3$ and CIS were prepared by the random prime labelling system, Rediprime II (Amersham Pharmacia Biotech, UK) and then purified from the free nucleotides with Nick Columns (Amersham Pharmacia Biotech $\mathrm{AB}$, Sweden) according to the suppliers' instructions.

The blots were prehybridised with NorthernMax prehyb/hyb Buffer (Ambion Inc., Austin, TX, USA) for $4 \mathrm{~h}$ at $50^{\circ} \mathrm{C}$ before a ${ }^{32} \mathrm{P}$ labelled probe was added. Blots were then hybridised for $16 \mathrm{~h}$ at the same temperature. After hybridisation, the blots were washed in $2 \times \mathrm{SSC} / 0.1 \% \mathrm{SDS}$ at $65^{\circ} \mathrm{C}$ for $30 \mathrm{~min}$, twice. Autoradiography was then carried out at $-70^{\circ} \mathrm{C}$ using Super HR-G30 X-Ray Film (Fuji Photo Film, Tokyo, Japan). Blots were finally stripped and rehybridised with a ${ }^{32} \mathrm{P}$-end-labelled oligomer probe specific for $18 \mathrm{~S}$ ribosomal RNA to ensure equal loading.

\section{Immunoblot}

Confluent cultures of breast cancer lines were scraped and homogenised on ice in RIPA buffer $\left(150 \mathrm{mmoll}^{-1} \mathrm{NaCl}, 1 \%\right.$ NP40, $0.5 \%$ sodium deoxycholate, $0.1 \%$ SDS, $50 \mathrm{~mm}$ Tris ( $\mathrm{pH} 7.5)$ ) with Complete protease inhibitor cocktail (Roche Molecular Biochemicals, Mannheim, Germany; cat 1697498). Lysates were then homogenised with a Polytron homogeniser for four $15 \mathrm{~s}$ pulses at maximum speed on ice, boiled for $10 \mathrm{~min}$ with $0.5 \mathrm{vol}$ of $3 \times$ Laemmli sample buffer and centrifuged at 15000 r.p.m. for $20 \mathrm{~min}$. Protein samples $(100 \mu \mathrm{g})$ were immunoblotted as previously described (Tam et al, 2001). After semidry transfer, nitrocellulose membranes were blocked with TBS (pH 8.0) containing 5\% skim milk, $0.1 \%$ Tween 20 and probed with goat anti-CIS antibody $(1: 250$, Santa Cruz Biotechnology; cat. sc-1529) at $4{ }^{\circ} \mathrm{C}$ overnight. Thereafter, membranes were incubated with HRP conjugated rabbit anti-goat antibody (Pierce, Rockford, IL, USA) at $1: 16000$ for $1 \mathrm{~h}$ at room temperature followed by development with West Pico Chemiluminescence Substrate (Pierce, Rockford, IL, USA).

\section{Immunohistochemistry}

Sections were dewaxed, rehydrated and pretreated with $3 \% \mathrm{H}_{2} \mathrm{O}_{2}$. They were then blocked with $10 \%$ normal horse serum, followed either by 1:500 rabbit anti-CIS antiserum (a gift from A Yoshimura) or 1:500 rabbit anti-SOCS anti-serum (a gift of Dr $\mathrm{D}$ Hilton) or 1:500 non-immune rabbit serum (as negative control), overnight at $4{ }^{\circ} \mathrm{C}$. Thereafter, sections were incubated with 1:200 biotinylated donkey anti-rabbit IgG (cat. RPN1004, Amersham, UK) for $2 \mathrm{~h}$ at room temperature, followed by $1: 200$ streptavidin-biotinylated HRP complex (cat. RPN 1051, Amersham, UK) for $2 \mathrm{~h}$ at room temperature. The signal was visualised by incubation with diaminobenzidine substrate for $5 \mathrm{~min}$. Sections were counterstained with haematoxylin and dehydrated before mounting.

\section{ERK reporter assay}

This was carried out in CHO cells as described in Clarkson et al (1999) using a luciferase coding sequence downstream of an egr-1 promoter fragment comprising $624 \mathrm{bp} 5^{\prime}$ of the initiation codon. CHO K1 cells seeded at $3 \times 10^{5}$ cells per well of a six-well plate and were transfected with DOTAP at a final DNA concentration of $4 \mu \mathrm{g}$ per well. This comprised $1 \mu \mathrm{g}$ of the reporter construct and $0,3,10$, $30,100,300,1000$ and $3000 \mathrm{ng}$ of the CIS expression vector (pCDNA3). Empty vector was added to make the total up to $3 \mu \mathrm{g}$ in all cases. The medium was changed at $18 \mathrm{~h}$, the cells were then left for $48 \mathrm{~h}$ in $0.125 \%$ serum supreme (Biowhittaker, Walkersville, MD, USA) in Hams' medium before harvesting for luciferase assay as described in Clarkson et al (1999).

\section{RESULTS}

\section{Breast cancer tissues}

In situ hybridisation: Overview Gene expression of different SOCS and CIS mRNAs in breast disorders was visualised through hybridisation between labelled probe and target mRNA, apparent as variable grey levels on film (Figure 1) and bright silver grains on tissue sections (Figure 2). The results obtained were always qualitatively consistent. The specificity of the signal was demonstrated by use of the controls described in the Materials and Methods. Thus, no specific signal could be detected after hybridisation with unrelated labelled cDNA probe or when cold probe was used as competitor (Figure 2A, B). Expression of the four genes was localized to identical areas but with variable intensity as shown by the quantitative analysis (Figure 3). Consequently, only typical results are shown (Figures 1 and 2).

Regional expression In normal breast tissue obtained at a distance from the tumour, the macroautoradiographic hybridisation signal for SOCS-1-3 and CIS mRNA was observed in regions corresponding to epithelial component of the duct (Figure 1B-E). A weak, homogeneous signal associated with the whole connective tissue area appeared to be specific in comparison to control sections hybridised with unrelated cDNA probe (not shown) and presumably represents the physiological level of SOCS-1-3 and CIS expression.

Higher expression of SOCS-1 -3 and CIS genes was evidenced in ducts enlarged by tumour cell proliferation and in the periductal reactive stroma. On sections obtained from patients with in situ breast carcinoma, this signal decreased in connective tissue located at a distance from the cancerous ducts (Figure $1 \mathrm{G}-\mathrm{J}$ ). In sections obtained from patients with infiltrating breast carcinoma, SOCS-1-3, and CIS transcript expression was stronger in the region corresponding to the most active zone of the tumour (Figure 1L-O).

Semiquantitative analysis of $m R N A$ Relative level of SOCS-1 (Figure 3A), SOCS-2 (Figure 3B), SOCS-3 (Figure 3C) and CIS (Figure 3D) mRNA expression was measured densitometrically on autoradiographic films on normal and pathologic breast sections, in areas selected as defined in Materials and Methods. Note that the signal intensities obtained for each mRNA cannot be 
A Normal breast tissue

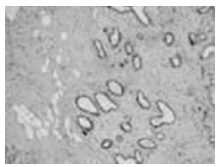

\section{F}
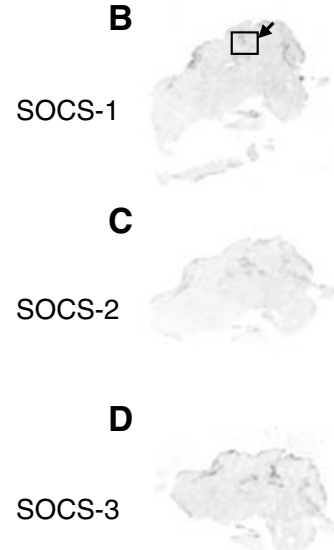

B

H

G
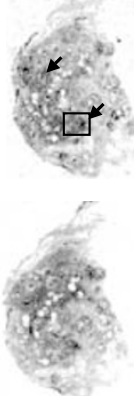

I

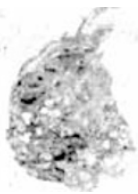

E

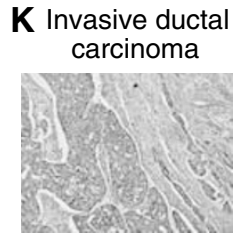

$\mathbf{L}$

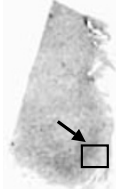

M

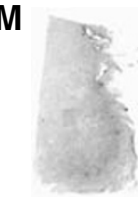

$\mathbf{N}$

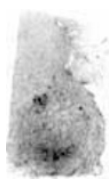

0

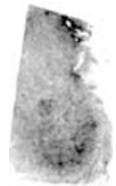

Figure I Macroautoradiographic pattern of ISH of SOCS-I-3, CIS mRNA performed on sections of normal breast $(\mathbf{A}-\mathbf{E})$ and typical lesions of in situ $(\mathbf{F}-\mathbf{J})$ and invasive $(\mathbf{K}-\mathbf{O})$ ductal carcinomas. Semiquantitative expression of mRNA was performed on typical areas of the samples, as illustrated in $\mathbf{B}, \mathbf{G}$ and $\mathbf{L}$, after precise microscopic examination of the contiguous HPS-stained sections ( $\mathbf{A}, \mathbf{F}$ and $\mathbf{K}$ ). The signal (dark areas) corresponds to different levels of SOCS and CIS genes expression. On adjacent sections of normal breast tissue, the signal obtained for the four genes is localised to the ducts and lobules (arrow) (B-E). On adjacent sections of in situ ductal carcinoma, the same intense signal is observed for the four genes and is localized to areas corresponding to enlarged ducts and periductal stroma reaction (arrows) $(\mathbf{G}-\mathbf{J})$. On adjacent sections of invasive ductal carcinoma, the increased density observed with the four probes encompasses the area corresponding to tumour cells infiltrating the cellular stroma $(\mathbf{L}-\mathbf{O})$. Thus, a more intense signal is seen specifically localised to the area of tumour invasion (arrow). Bar, $5 \mathrm{~mm}$.

compared, since the four different probes did not hybridise with the same efficiency.

In normal breast tissue, the hybridisation signal was stronger in the epithelial ducts than the connective tissue, and this was seen for all probes except SOCS-2 (Figure 3A-D). On the pathologic sections, we consistently observed that SOCS-1-3 and CIS gene expression was strongly associated with the tumor cells and was significantly higher than the basal level in normal adjacent epithelial and connective tissues $(P<0.05)$.

SOCS-1 gene expression increased in the cancerous ducts $(+22 \%$ vs normal ducts, $P<0.05)$ and in the reactive stromal area $(+104 \%$ vs adjacent connective tissue, $P<0.01)$ of sections obtained from patients with in situ ductal carcinoma (Figure $3 \mathrm{~A}$ ). SOCS-2 gene expression more significantly increased in the cancerous cells $(+135 \%$ vs normal duct, $P<0.05)$ of in situ ductal carcinoma, as well as in the tumoral area of infiltrating carcinoma $(+50 \%$ vs normal duct, $P<0.05)$ (Figure 3B). SOCS-3 gene expression significantly increased in the cancerous ducts $(+32 \%$ vs normal duct, $P<0.05)$ and in the reactive stromal area $(+170 \%$

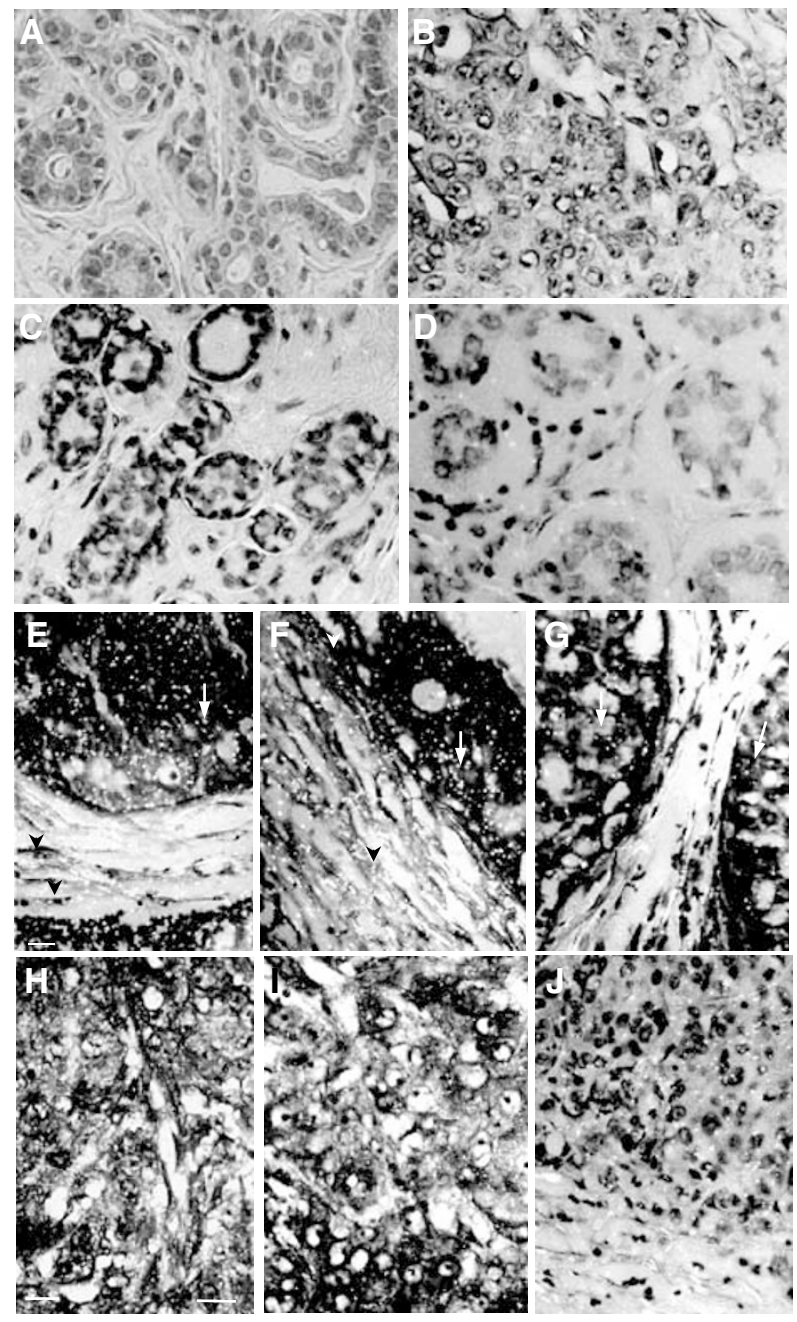

Figure 2 Cellular expression of SOCS- $1-3$ and CIS mRNA in normal breast $(\mathbf{A}, \mathbf{C}, \mathbf{D})$, in situ $(\mathbf{E}-\mathbf{G})$ and invasive $(\mathbf{H}-\mathbf{J})$ ductal breast carcinomas, evidenced by the presence of bright silver grains on emulsioncoated sections. On sections of normal breast tissue, basal levels of SOCS-

I (C) and CIS (D) were detected in normal epithelial cells and in scattered fibroblasts of the surrounding connective tissue. On sections from patients with in situ ductal carcinoma, expression of SOCS-I (E), SOCS-2 (F) and $\mathrm{CIS}(\mathbf{G})$ transcripts was strongly associated with proliferative tumour cells (arrows) of the enlarged ducts, in concentric layers of fibroblastic cells (arrowheads) and in lymphocytes of inflammatory infiltrates (*). On sections from patients with invasive ductal carcinoma, gene expression of SOCS-I (H), SOCS-3 (I) and CIS (J) was abundantly detected in the whole area of the tumour. The close association of cancerous cells and stromal cells prevents the precise identification of the positive cell component. No signal was observed when in situ hybridisation was performed with heterologous cDNA probe as a negative control on normal breast tissue $(\mathbf{A})$ and invasive ductal carcinoma (B). Bar, $50 \mu \mathrm{m}$.

$v s$ adjacent connective tissue, $P<0.01$ ) of in situ ductal carcinoma, as well as in tumour area of sections obtained from patients with infiltrating carcinoma $(+39 \%$ vs normal duct, $P<0.05)$ (Figure 3C). CIS gene expression was strongly increased in tumour cells $(+120 \%$ vs normal ducts, $P<0.01)$ of in situ ductal carcinoma, as well as in tumour area of sections obtained from patients with infiltrating carcinoma $(+60 \%$ vs normal ducts, $P<0.05)$. CIS expression was also elevated in adjacent reactive stroma relative to normal tissue (Figure 3D).

Cellular patterns of SOCS-1-3 and CIS gene expression To determine which cell components expressed SOCS-1-3 and CIS 

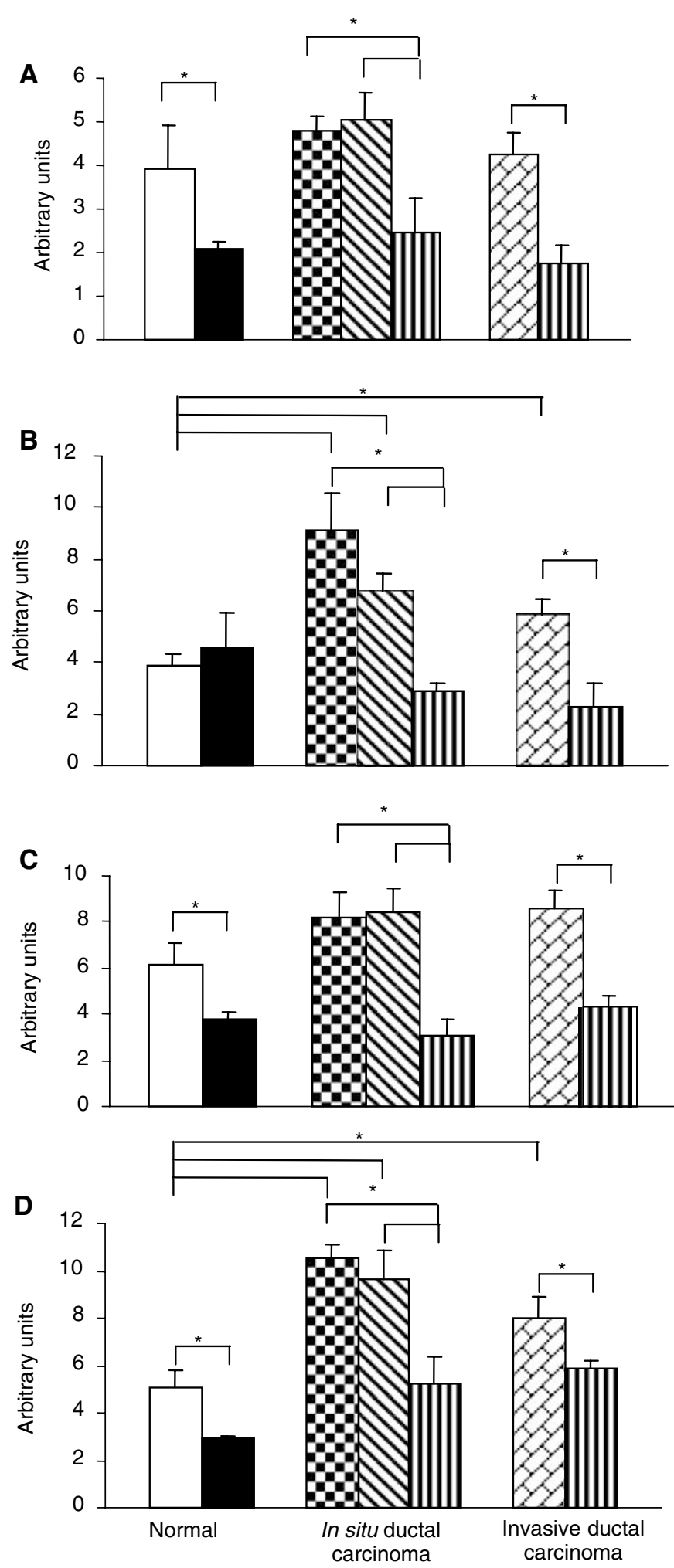

Figure 3 Quantification of mRNA levels was performed on macroautoradiograms from normal breast, in situ and invasive ductal carcinomas as described in Materials and Methods. Optical densities were measured for the four probes (A: SOCS-I, B: SOCS-2, C: SOCS-3, D: CIS) in typical areas according to pathological criteria: $(\square)$, normal duct; $(\mathbf{\square})$, normal connective tissue; $(\boldsymbol{\nabla})$, cancerous ducts; $(\mathbf{\nabla})$, reactive stroma; $(\mathbb{\nabla})$, invasive area; (III), adjacent normal connective tissue; expressed in arbitrary units \pm s.e.m. $* P<0.05$.
mRNA in normal and pathologic human breast, microautoradiographic methodology was utilized as previously described (Mertani et al, 1998). Basal levels of SOCS-1 (Figure 2C), SOCS-2, -3 (not shown) and CIS (Figure 2D) mRNA were detected in both luminal epithelial and myoepithelial cells of normal ducts and in scattered fibroblasts of the surrounding normal stroma.

In sections from patients with intraductal breast carcinoma, the expression of the four genes was localised to cancerous cells as well as to cells of the reactive stroma surrounding the ducts (Figure $2 \mathrm{E}-\mathrm{G}$ ), as was evident with the macroautoradiographic study described above (Figure $1 \mathrm{G}-\mathrm{J}$ ). In this reactive stroma, concentric layers of myoepithelial and myofibroblastic cells showed an intense signal. The stroma was often infiltrated by numerous inflammatory cells which were also strongly labelled (Figure 2E). As reflected by the semiquantitative data (Figure 3), there was no difference in signal intensity between the signal obtained in the tumour cells and the periductal reactive stroma (Figure $2 \mathrm{E}-\mathrm{G}$ ).

In sections obtained from patients with infiltrating ductal breast carcinoma, gene expression of SOCS-1, -2, -3 and CIS was associated with the entire area of the tumour invasion (Figure $2 \mathrm{H}-\mathrm{J})$. The tumour architecture and the stromal disorganization of this type of breast cancer limited clear distinction between silver grains associated with tumour cells and stromal cells accompanying the tumour progression.

Immunohistochemistry CIS immunoreactivity was weak in normal duct luminal epithelium and myoepithelial cells, positive in blood vessels, and strongly positive in carcinoma (Figure 4, panels $\mathrm{A} 1$ and A2). Fibroblasts of connective tissue did not show significant CIS immunoreactivity. Immunoreactivity for SOCS-3 was similar to that for CIS, with carcinoma staining more prominent than in normal epithelium, although staining in blood vessels was not as evident (Figure 4, panels B1 and B2). Both in the case of CIS and for SOCS-3, no immunoreactivity was seen when nonimmune serum was run in parallel sections (not shown).

\section{Breast cancer lines}

Northern analysis for SOCS transcripts A survey of 10 breast cancer lines for SOCS-1-3 and CIS transcripts showed that only CIS mRNA was elevated in all transformed lines in comparison with the two phenotypically normal lines, HMEC184 and MCF10A. There was no correlation between CIS transcript expression and GH receptor mRNA expression across these lines (Figure 5). Prolactin receptor mRNA was expressed in all but one of the transformed lines and not in the two control lines, but the level of prolactin receptor expression did not correlate with the level of CIS mRNA across these lines (Figure 5). It is possible that endogenous or exogenous prolactin could elevate CIS transcripts in these lines, but the lack of correlation between CIS transcript levels and expression of other SOCS transcripts argues against this, given that prolactin is able to induce SOCS-1,-3 and CIS transcripts in mammary tisue (Tam et al, 2001).

Immunoblot analysis Immunoblot of cell lysates from these breast cancer lines for CIS protein revealed a high level of expression of bands around 47000 and 32000 for all cancer lines (Figure 6). The 47000 bands correspond to those of the ubiquitinylated form of CIS (Tauchi et al, 2001), and were more intense than the 32000 band in all cases except for MDA-MB-468 and ZR 75-30 lines. These bands were absent in the MCF-10A control line, corresponding to its lack of CIS transcripts. Note that the FLAG tagged CIS control runs more slowly because of the contribution from the tag.

In order to determine if expression of the CIS protein was dependent on serum factors, including prolactin and $\mathrm{GH}$, the breast cancer lines were deprived of serum for $12 \mathrm{~h}$ before harvesting for immunoblot analysis. As can be seen in Figure 7, 


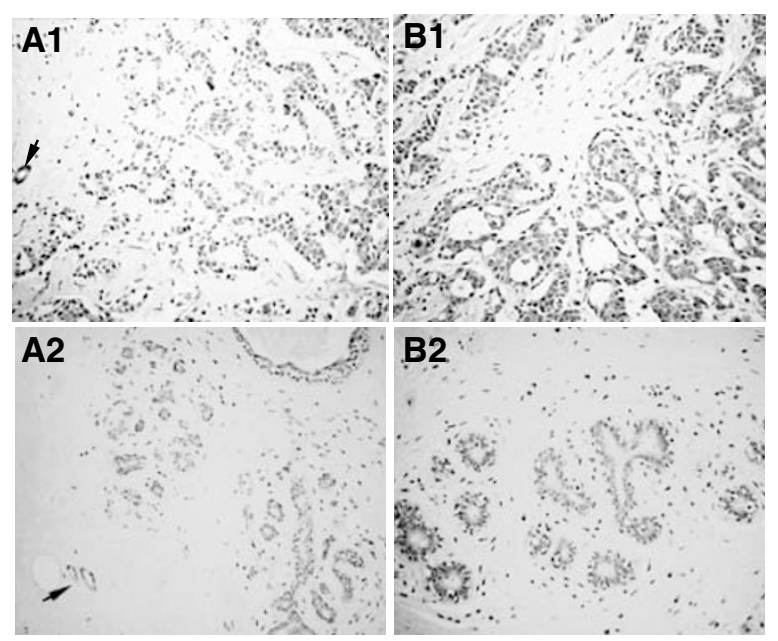

Figure 4 Immunostaining for $\mathrm{CIS}$ and SOCS-3 in normal breast tissue and infiltrating ductal carcinoma. Tissues were fixed and processed as described in the Materials and Methods section. Cancerous cells were strongly immunoreactive for CIS (AI) and SOCS-3 (BI) when compared with normal tissues (A2 and B2, respectively). Arrows indicate equal immunoreactivity in blood vessels of normal and cancerous tissue. Bar, $100 \mu \mathrm{m}$.

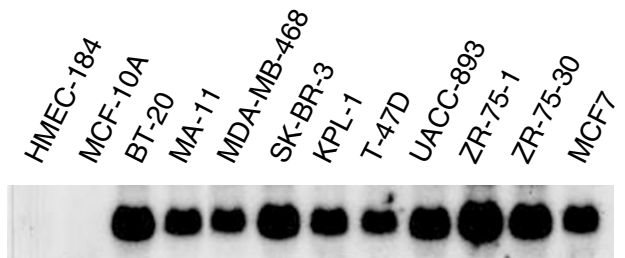

CIS

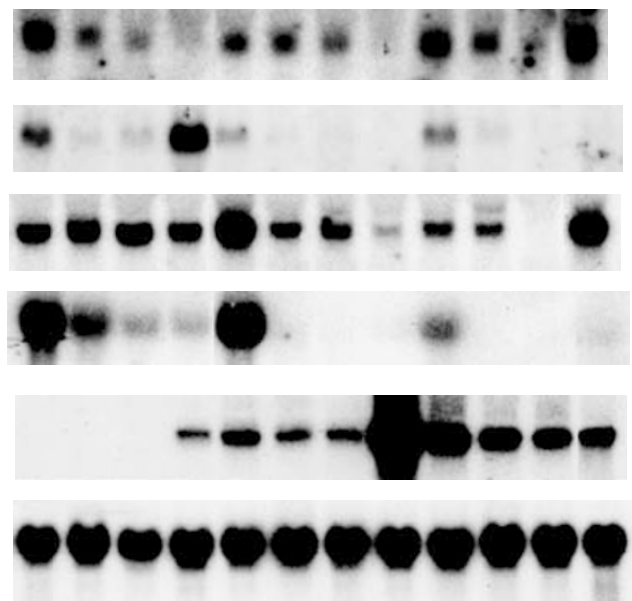

SOCS-1

socs-2

SOCS-3

hGH-R

hPRL-R

$18 S$

Figure 5 Expression of transcripts for $\mathrm{CIS}$ and SOCS- I-3 and for $\mathrm{GH}$ and prolactin receptors in normal (HMECI84 and MCF-IOA) and 10 breast cancer lines. Total RNA was extracted from cell lines, subjected to electrophoresis on a formaldehyde gel and blotted on a nylon membrane. Identical blots were run and each was hybridized with a specific cDNA probe. The blots were then washed and exposed to X-ray films as described in Materials and Methods. The exposure time for CIS was 2 days; for SOCS-I, 5 days; for SOCS-2, 5 days; and for SOCS-3, 3 days. Blots were stripped and reprobed for I8S rRNA to ensure equal loading.

serum deprivation was without effect on CIS protein expression in the lines we examined.

ERK reporter assay This was carried out with a luciferase reporter construct that possesses five SRF/Ets response elements,

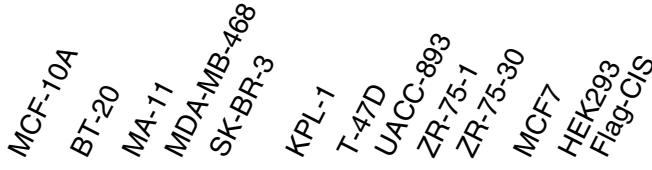

$42.6 \mathrm{kDa}-$

$31.7 \mathrm{kDa}-$

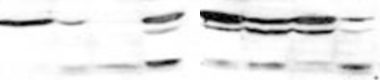

Figure $6 \mathrm{CIS}$ protein expression in breast cancer lines. Total cell lysate was obtained from confluent cultures of breast cancer lines or normal lines. Lysates were then immunobloted and probed with goat anti-CIS antibody as described in the Materials and Methods. FLAG-tagged CIS expressed in HEK 293 cells was used as a positive control. Signal corresponding to the CIS protein was detected migrating at $32 \mathrm{kDa}$ in breast cancer cell lines. Another slower migrating band at $47 \mathrm{kDa}$ corresponds to the ubiquitinylated form of CIS.

\section{$31.7 \mathrm{kDa}^{-}$}

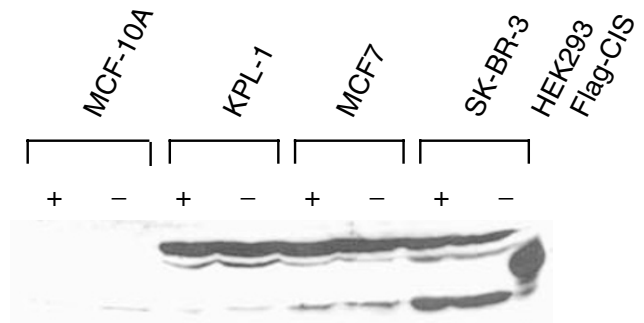

Figure 7 Lack of effect of serum on expression of CIS protein in breast cancer lines. Cells were exposed to $10 \%$ serum or serum starved for $12 \mathrm{~h}$ before harvesting for immunoblot analyses as for Figure 6.

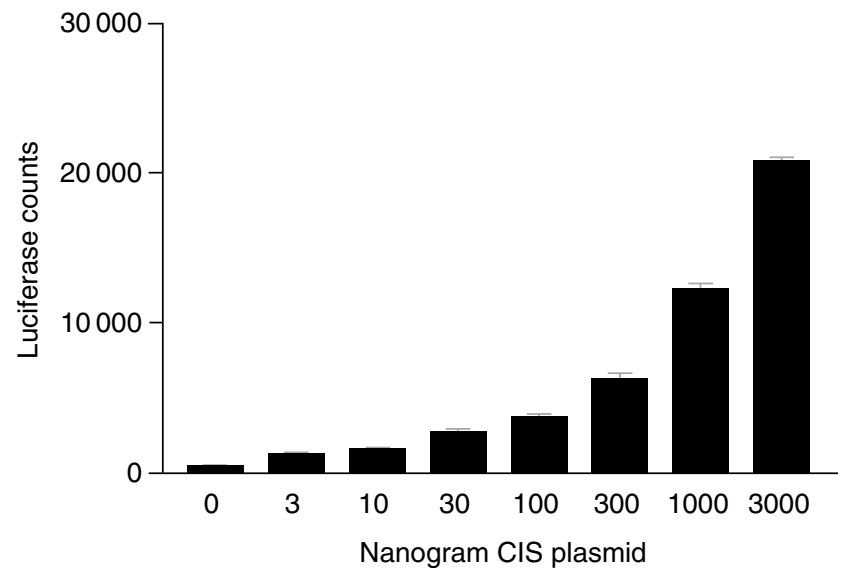

Figure $8 \mathrm{CIS}$ transfection results in elevated ERK reporter activity. $\mathrm{CHO}$ cells were transfected with increasing amounts of CIS expression plasmid and an ERK reporter plasmid. The total amount of DNA was normalised to $3 \mu \mathrm{g}$ with empty pcDNA3. Luciferase assay was carried out as described in the Materials and Methods section. Luciferase counts expressed as mean \pm s.e.m., four replicates per point. This result was obtained on three separate occasions.

which are responsive to ERK stimulation through phosphorylation of Elk-1 and Sap1a (Gille et al, 1995; Janknecht and Hunter, 1997), but has no STAT5 response elements (Clarkson et al, 1999). As shown in Figure 8, transfection with an increasing level of CIS expression plasmid results in increased ERK reporter activity. The effect is substantial, fold inductions at $3 \mu \mathrm{g}$ CIS plasmid being 57-, 55- and 27-fold in three independent assays. 


\section{DISCUSSION}

The present study demonstrates that SOCS-1, -2, -3 and CIS mRNAs are expressed more strongly in human breast carcinoma. We have identified the cell types expressing SOCS and CIS mRNA, and quantified the relative levels of expression in human breast tumours of increasing severity from a preinvasive stage (ductal carcinoma) to invasive carcinoma, for which we have previously documented the gene expression levels for both GH and PRL receptors (Mertani et al, 1998).

In the normal human breast, lower levels of SOCS and CIS mRNA were found in both ductal epithelial cells and the fibroblastic component. This level of gene expression was also found in normal tissue located at a distance from the tumour in all the pathologic samples examined. Our results show upregulation of SOCS and CIS gene expression in malignant breast disorders. In ductal breast carcinoma, SOCS-2 and CIS gene expression was particularly strong in tumour cells within the ducts, which were isolated from the reactive stroma by the myoepithelial barrier. This result can be compared to the elevated CIS gene expression level seen in vitro with breast cancer lines. Surrounding the cancerous ducts, stronger gene expression was also evidenced in the region of reactive stroma showing features of fibrogenesis and immune activation. High levels of SOCS-1-3 and CIS gene expression were associated with the fibroblasts, inflammatory cells and endothelial cells of the neovascularisation, which essentially comprises the reactive stroma. The local host defense is particularly important during the progression period from in situ to invasive ductal carcinoma and is characterised by intense cytokine production from the lymphocytic infiltration. Thus, a study by Camp et al (1996) performed on 89 human breast carcinomas showed strong lymphocytic production of Il-2, Il-4, TGF- $\beta 1$, TNF- $\alpha$ as well as lower levels of IFN $\gamma$ and GM-CSF. These cytokines are major activators of SOCS/CIS signalling, particularly SOCS-1 and -3 in granulocytes and lymphocytes (Hilton, 1999; Dogusan et al, 2000).

In addition to the conventional inflammatory cytokines, PRL and $\mathrm{GH}$, the major mammotrophic hormones, may be involved in SOCS gene induction during breast carcinogenesis. These are also known to induce substantial SOCS-1-3 and CIS gene expression (Adams et al, 1998; Tam et al, 2001). The presence of GH and PRL receptors in both epithelial and stromal cells has been previously shown in the normal human breast and in various benign and malignant human breast disorders (Clevenger et al, 1995; Mertani et al, 1998; Gebre-Medhin et al, 2001). Recent studies have shown the importance of autocrine/paracrine production of hGH and hPRL during human breast carcinoma cell proliferation in vitro (Kaulsay et al, 1999; Mertani et al, 2001) and have proposed that local production of PRL in vivo is more important than systemic PRL for the tumour formation (reviewed in Wennbo and Tornell, 2000). We have demonstrated in vivo hGH production from human breast carcinoma and established that increased expression of the hGH gene occurs in the epithelial component and that de novo stromal expression of hGH is associated with the neoplastic progression of the mammary gland (Raccurt et al, 2002). Other studies (Hattori et al, 1990; Wu et al, 1996) have shown that human lymphocytes express abundant hGH mRNA. These considerations and our present results, suggest that autocrine/ paracrine $\mathrm{GH}$ and/or PRL in the reactive stroma of ductal carcinoma may be inducers of SOCS gene expression in vivo.

In order to establish whether this SOCS overexpression is intrinsic to the transformed breast cancer cell or a result of hosttumour interaction, we also examined 10 breast cancer lines for SOCS gene expression. However, only CIS gene expression was elevated in all of these lines, but not in the two control breast lines. Immunoblots showed a high level of expression of ubiquitinylated CIS or CIS protein in the cancer lines, whereas neither form of CIS was detected in the control line. Level of protein expression of CIS was not affected by serum starvation, suggesting that elevated CIS expression is intrinsic to these breast cancer lines, and does not require serum factors such as $\mathrm{hGH}$, prolactin or colony-stimulating factors. Accordingly, there was no correlation between level of gene expression for either hGH receptor or prolactin receptor and CIS gene expression across these lines.

Given the ubiquitous nature of SOCS gene expression in response to host cytokines, and the above candidate inducers, it is not unexpected that breast tumour tissue shows elevated SOCS expression. However, the elevation of CIS expression is independent of host responses, and appears to be intrinsic to the breast cancer line itself. What might be the significance of this elevation? We suggest that it serves at least a two-fold purpose: (1) to activate the proliferative MAP/ERK kinase pathway and (2) to block STAT 5-mediated responses to trophic hormones, which maintain normal differentiated breast cell phenotype as exemplified by the lack of mammary gland development in CIS transgenic mice (Matsumoto et al, 1999). Activation of MAP kinases (ERK, JNK) has been shown to be an important consequence of CIS overexpression in CD4 T cells ( $\mathrm{Li}$ et al, 2000), and is thought to be a result of direct association between CIS and PKC theta, since this PKC is able to activate MAP kinases (Baier-Bitterlich et al, 1996). We have confirmed that chronically elevated CIS is able to elevate ERK activity in an ERK responsive promoter assay, and find induction of luciferase reporter activity proportional to the amount of cotransfected CIS expression vector. A coordinated increase in ERK activation and inhibition of STAT5 activation by CIS could allow it to act as a switch, promoting proliferation while blocking differentiated breast cell function. An additional role for the constitutively elevated CIS may be to decrease breast cancer sensitivity to interferons, similar to the decreased sensitivity to IFN $\gamma$ seen in cutaneous T-lymphoma (CTCL) cell lines that constitutively express SOCS-3 (Brender et al, 2001).

The alteration responsible for elevated CIS gene and protein expression is unclear, but given that the major factor thought to be responsible for induction of CIS by cytokines is STAT 5 (Verdier et al, 1998), the increased CIS expression may be linked to escape from STAT 5-mediated induction of its promoter. This is supported by our preliminary studies that show low or undetectable STAT 5 in the breast cancer lines studied here (Tam, Lau, Waters, unpublished). Other transcription factors have been shown to interact with the CIS promoter such as Ets factors $\mathrm{GABP} \alpha / \beta$ and $\mathrm{NF} \kappa \mathrm{B}$, and deletion of STAT 5 elements in the proximal human CIS promoter still results in substantial levels of basal activity (Verdier et al, 1998), so other cis acting factors may be important in maintaining CIS expression in these breast cancer cells.

The significance of the strongly elevated level of ubiquitinylated CIS is unclear, but may relate to the ability of CIS to promote destruction of cytokine-cytokine receptor complexes via the ubiquitin-proteasome pathway (Tauchi et al, 2001). This has been shown to substantially decrease cell sensitivity to the relevant cytokine (Ram and Waxman, 2000; Tauchi et al, 2001).

In conclusion, we report elevation of SOCS-1-3 and CIS in breast cancers in vivo. In breast cancer lines, only CIS gene expression was elevated, and this could have important consequences for breast cancer phenotype and proliferative ability. Given this observation, agents blocking the production or action of CIS could be of therapeutic benefit in breast cancer.

\section{ACKNOWLEDGEMENTS}

This work was supported by grants from the Queensland Cancer Fund to MJW and from 'Ligue Contre le Cancer, Comite de Savoie' to GM. 


\section{REFERENCES}

Adams TE, Hansen JA, Starr R, Nicola NA, Hilton DJ, Billestrup NJ (1998) Growth hormone preferentially induces the rapid, transient expression of SOCS-3, a novel inhibitor of cytokine receptor signaling. J Biol Chem 273: $1285-1287$

Allione A, Consalvo M, Nani P, Lollini PL, Cavallo F, Giovarelli M, Forni M, Gulino A, Colombo MP, Dellabona P (1994) Immunizing and curative potential of replicating and non-replicating murine mammary adenocarcinoma cells engineered with interleukins $-2,-4,-6,-7,-10$, tumor necrosis factor $\alpha$, GMCSF and $\gamma$ interferon gene or admixed with conventional adjuvants. Cancer Res 54: 6022-6026

Argetsinger LS, Carter-Su C (1996) Mechanism of signaling by GH receptor. Physiol Rev 4: 1089-1107

Baier-Bitterlich G, Uberall F, Bauer B, Fresser F, Wachter H, Grunicke H, Utermann G, Altman A, Barier G (1996) Protein kinase C-theta isoenzyme selective stimulation of the transcription factor complex AP-1 in T-lymphocytes. Mol Cell Biol 16: $1842-1850$

Boutin JM, Edery M, Shirota M, Jolicoeur C, Lesueur L, Ali S, Gould D, Djiane J, Kelly PA (1989) Identification of a cDNA encoding a long form of prolactin receptor in human hepatoma and breast cancer cells. $\mathrm{Mol}$ Endocrinol 3: 1455 - 1461

Brender C, Nielsen M, Kaltoft K, Mikkelsen G, Zhang Q, Wasik M, Billestrup N, Odum N (2001) STAT3 mediated constitutive expression of SOCS-3 in cutaneous T-cell lymphoma. Blood 97: $1056-1062$

Camp BJ, Dyhrman ST, Memoli VA, Mott LA, Barth RJ (1996) In situ cytokine production by breast cancer tumor-infiltrating lymphocytes. Ann Surg Oncol 3: 176-184

Clarkson RWE, Shang CA, Levitt LK, Howard T, Waters MJ (1999) Ternary complex factors Elk-1 and Sap-1a mediate GH induced transcription of Egr-1 in 3T3-F442A preadipocytes. Mol Endocrinol 13: 619-631

Clevenger CV, Chang W-P, Ngo W, Pasha TLM, Montone KT, Tomaszewski JE (1995) Expression of prolactin and prolactin receptor in human breast carcinoma. Am J Pathol 146: 695-705

Dogusan Z, Hooghe-Peters EL, Bers D, Velkeniers B, Hooghe R (2000) Expression of SOCS genes in normal and leukemic human leukocytes stimulated by prolactin, growth hormone and cytokines. J Neuroimmunol 109: 34-39

Emanuelli B, Peraldi P, Filloux C, Sawka-Verhelle D, Hilton D, Van Obberghen E (2000) SOCS-3 is an insulin-induced negative regulator of insulin signaling. J Biol Chem 275: 15985-15991

Fuh G, Wells JA (1995) Prolactin receptor antagonists that inhibit the growth of breast cancer lines. J Biol Chem 270: $13133-13137$

Gebre-Medhin M, Kindblom LG, Wennbo H, Törnell J, Meis-Kindblom JM (2001) Growth hormone receptor is expressed in human breast cancer. Am J Pathol 158: 1217-1222

Gille H, Kortenjann M, Thomae O, Moomaw C, Slaughter C, Cobb MH, Shaw PE (1995) ERK phosphorylation potentiates Elk-1 mediated ternary complex formation and transactivation. EMBO $J$ 14: $951-962$

Godowski PJ, Leung DW, Meacham LR, Galgani JP, Hellmiss R, Keret R, Rotwein PS, Parks JS, Laron Z, Wood WI (1989) Characterization of the human growth hormone receptor gene and demonstration of a partial gene deletion in two patients with Laron-type dwarfism. Proc Natl Acad Sci USA 86: $8083-8087$

Hankinson SE, Willett WC, Michard DS, Manson JE, Colditz GA, Langcope C, Rosner B, Speizer FE (1999) Plasma prolactin levels and subsequent risk of breast cancer in postmenopausal women. J Natl Cancer Inst 91: $629-634$

Harvat BL, Jetten AM (1996) Gamma interferon induces an irreversible growth arrest in mid G1 in mammary epithelial cells which correlates with a block in hyperphosphorylation of Rb. Cell Growth Differ 7: $289-300$

Hattori N, Shimatsu A, Sugita M, Kumagai S, Imura H (1990) Immunoreactive growth hormone $(\mathrm{GH})$ secretion by human lymphocytes: augmented release by exogenous GH. Biochem Biophys Res Commun 168: 396-401

Hilton DJ (1999) Negative regulators of cytokine signal transduction. Cell Mol Life Sci 55: $1568-1577$

Janknecht R, Hunter T (1997) Convergence of MAP kinase pathways on the ternary complex factor Sap 1a. EMBO J 16: 1620-1627

Kamizono S, Hanada T, Yasukawa H, Minoguchi S, Kato R, Minoguchi M, Hattori K, Hatakeyama S, Yada M, Morita S, Kitamura T, Kato H, Nakayama K, Yoshimura A (2001) The SOCS box of SOCS-1 accelerates ubiquitin dependent proteolysis of TEL-JAK2. J Biol Chem 276: $12530-12538$

Kaulsay KK, Mertani HC, Tornell J, Morel G, Lee K-O, Lobie PE (1999) Autocrine stimulation of human mammary carcinoma cell proliferation by hGH. Exp Cell Res 250: 35-50

Li S, Chen S, Xu X, Sundstedt A, Paulsson KM, Anderson P, Karlsson S, Sjogren H-O, Wang P (2000) CIS promotes $\mathrm{T}$ cell receptor mediated proliferation and prolongs survival of activated T cells. J Exp Med 191: 985-994

Matsumoto A, Masuhara M, Mitsui K, Yokouchi M, Ohtsubo M, Misawa H, Miyajima A, Yoshimura A (1997) CIS, a cytokine inducible SH2 protein, is a target of the JAK-STAT5 pathway and modulates STAT5 activation. Blood 89: $3148-3154$

Matsumoto A, Seki Y, Kubo M, Ohtsuka S, Suzuki A, Hayashi I, Tsuji K, Nakahata T, Okabe M, Yamada S, Yoshimura A (1999) Suppression of STAT5 functions in liver, mammary glands, and $\mathrm{T}$ cells in cytokineinducible $\mathrm{SH} 2$-containing protein 1 transgenic animals. Mol Cell Biol 19: $6396-6407$

Maus MV, Reilly SC, Clevenger CV (1999) Prolactin as a chemoattractant for human breast carcinoma. Endocrinology 140: $5447-5450$

Mertani HC, Zhu T, Bennet W, Lee K, Lobie PE (2001) Autocrine human growth hormone $(\mathrm{hGH})$ regulation of human mammary carcinoma cell gene expression. Identification of CHOP as a mediator of hGH stimulated human mammary carcinoma cell survival.. J Biol Chem 276: $21464-21475$

Mertani HC, Garcia-Caballero T, Lambert A, Gerard F, Palayer C, Boutin JM, Vonderhaar BK, Waters MJ, Lobie PE, Morel G (1998) Cellular expression of $\mathrm{GH}$ and prolactin receptors in human breast disorders. Int J Cancer 79: 202-211

Peyrol S, Raccurt M, Gérard F, Gleyzal C, Grimaud JA, Sommer P (1997) Lysyl oxidase gene expression in the stromal reaction to in situ and invasive ductal breast carcinoma. Am J Pathol 150: $497-507$

Raccurt M, Lobie PE, Moudilou E, Garcia-Caballero T, Frappart L, Morel G, Mertani HC (2002) High stromal and epithelial human GH gene expression is associated with proliferative disorders of the mammary gland. J Endocrinol 175: $307-318$

Ram PA, Waxman DJ (1999) SOCS/CIS protein inhibition of growth hormone-stimulated STAT5 signaling by multiple mechanisms. J Biol Chem 274: $35553-35561$

Ram PA, Waxman DJ (2000) Role of the cytokine-inducible SH2 protein CIS in desensitization of STAT5b signaling by continuous GH. J Biol Chem 275: $39487-39496$

Reynolds C, Montone KT, Powell CM, Tomaszewski JE, Clevenger CV (1997) Expression of prolactin and its receptor in human breast carcinoma. Endocrinology 138: 5555 - 5560

Sakamoto H, Yasukawa H, Masuhara M, Tanimura S, Sasaki A, Yuge K, Ohtsubo M, Ohtsuka A, Fujita T, Ohta T, Furukawa Y, Iwase S, Yamada $\mathrm{H}$, Yoshimura AA (1998) Janus kinase inhibitor, JAB, is an IFN- $\gamma$ inducible gene and confers resistance to inteferons. Blood 92: 1668-1676

Silberstein GB, Daniel CW (1987) Investigations of mouse mammary ductal growth regulation using slow release implants. J Dairy Sci 70: $1981-1990$

Song MM, Shuai K (1998) The SOCS1 and SOCS3 but not SOCS2 proteins inhibit interferon mediated antiviral and antiproliferative activities. $I$ Biol Chem 273: $35056-35062$

Starr R, Willson TA, Viney EM, Murray LJ, Rayner JR, Jenkins BJ, Gonda TJ, Alexander WS, Metcalf D, Nicola NA, Hilton DJ (1997) A family of cytokine-inducible inhibitors of signalling. Nature 387: 917-921

Tam SP, Lau P, Djiane J, Hilton DJ, Waters MJ (2001) Tissue-specific induction of SOCS gene expression by PRL. Endocrinology 142: $5015-5026$

Tannenbaum CS, Hamilton TA (2000) Immune-inflammatory mechanisms in IFN $\gamma$ mediated anti-tumor activity. Semin Cancer Biol 10: $113-123$

Teglund S, McKay C, Schuetz E, van Deursen JM, Stravopodis D, Wang D, Brown M, Bodner S, Grosveld G, Ihle JN (1998) Stat 5a and Stat 5b proteins have essential and nonessential, or redundant, roles in cytokine responses. Cell 93: $841-850$

Tauchi T, Yoshimura A, Ohyashiki K (2001) CIS1 suppresses BCR/ABLmediated transformation: involvement of the ubiquitin proteasome pathway. Exp Hematol 29: 356-361 
Vonderhaar BK (1987) Prolactin: transport, function, and receptors, in mammary gland development and differentiation. In The Mammary Gland: Development, Regulation and Function, Neville MC, Daniel CW (eds) pp 383-437. New York: Plenum Press

Verdier F, Rabionet R, Gouilleux F, Beisenherz-Hus C, Varlet P, Muller O, Mayeux P, Lacombe C, Gisselbrecht S, Chretien S (1998) A sequence of the CIS gene promoter interacts preferentially with two associated

STAT5A dimers: a distinct biochemical difference between STAT5A and STAT5B. Mol Cell Biol 18: $5852-5860$

Wennbo J, Tornell J (2000) The role of prolactin and growth hormone in breast cancer. Oncogene 19: 1072-1076

Wu H, Devi R, Malarkey WB (1996) Localization of growth hormone messenger ribonucleic acid in the human immune system-a clinical research center study. J Clin Endocrinol Metab 81: 1278-1282 